\title{
ARSITEKTUR BOARDGAME EDUKASI SEBAGAI UNSUR GAMIFIKASI PEMBELAJARAN UNTUK MEMBANGUN PARTISIPASI AKTIF, MOTIVASI, DAN MINAT BELAJAR SISWA
}

\author{
Moch. Hari Purwidiantoro ${ }^{1}$, Widiyanto Hadi ${ }^{2}$ \\ 1,2 STMIK Amikom Surakarta \\ 1'hari@dosen.amikomsolo.ac.id, ${ }^{2}$ widiyanto@dosen.amikomsolo.ac.id
}

\begin{abstract}
ABSTRAK
Tujuan penelitian ini untuk merancang dan mengembangkan media pembelajaran board game sebagai unsur gamifikasi pembelajaran untuk meningkatkan partisipasi aktif, motivasi dan minat belajar siswa. Board game adalah permainan yang menggunakan media papan sebagai media utamanya, permainan ini bisa digunakan untuk meningkatkan kerjasama serta dapat mengurangi kecenderungan dan ketergantungan peserta didik terhadap smartphone, tanpa mengurangi unsur fun,serta unsur edukasi yang ada dalam permainan. Dengan menggunakan board game sebagai unsur gamifikasi pembelajaran diharapkan dapat membuat peserta didik lebih menikmati pembelajaran, sehingga akan berdampak terhadap meningkatnya partisipasi aktif, motivasi serta minat belajar siswa yang menjadi unsur ketercapaian alam penelitian ini. Tahapan model pengembangan menggunakan model ADDIE (Analyze, Design, Develop, Implement, Evaluate) oleh Lee \& Owens. Implemantasi dan evaluasi menggunakan metode penelitian tindakan kelas.
\end{abstract}

Kata kunci: Board game; gamifikasi; media pembelajaran

\begin{abstract}
The purpose of this research is to develop and develop board game learning media as an element of gamification of learning to increase active participation, motivation and student interest in learning. Board games are board games as the main medium, this game can be used to increase cooperation and can reduce the tendency and dependence of students on smartphones, without reducing the fun and education in the game. By using board games as an element of learning gamification, it is expected that students enjoy learning, so that it will have more impact on active participation, motivation and student interest in learning which is the natural achievement of this research. The stages of the development model use the ADDIE (Analyze, Design, Develop, Implement, Evaluate) model by Lee \& Owens. Implementation and evaluation using classroom research methods.
\end{abstract}

Keywords: Board game, gamification, learning media.

\section{PENDAHULUAN}

Salah satu penunjang keberhasilan proses belajar mengajar yaitu penggunaan media pembelajaran. Media pembelajaran adalah sesuatu yang digunakan untuk menyampaikan pesan dari guru kepada peserta didik sehingga merangsang pikiran, perasaan, perhatian dan minat peserta didik untuk mencapai tujuan pembelajaran secara efektif (Sukiman, 2012). Levie \& Lents mengemukakan terdapat empat fungsi media pembelajaran, khususnya media visual, yaitu fungsi atensi, fungsi afektif, fungsi kognitif, dan fungsi kompensatoris (Arsyad, 2015).

Pada kegiatan belajar mengajar yang monoton membuat peserta didik cenderung merasa bosan dan jenuh dengan luasnya cakupan mata pelajaran yang harus diikuti, dengan banyaknya materi teori dan jam pembelajaran menyebabkan materi sulit dipahami. Hal tersebut ditambah sikap peserta didik yang kurang terkondisikan saat merasa bosan karena kurangnya partisipasi aktif 
peserta didik, motivasi dan minat belajar terhadap materi yang disajikan.

Permainan papan atau board game adalah jenis permainan yang dimainkan dengan menggunakan media papan sebagai alat utama permainannya. Permainan ini memiliki bentuk dan pola bermain yang beragam. Beberapa keunggulan board game yaitu : peraturan, interaksi sosial, edukasi, resiko, dan jenjang generasi. Sehingga board game merupakan permainan yang erat dengan fitur sosialisasi di antara pemainnya dan dapat dimainkan oleh berbagai kalangan usia.

Unsur fun yang ditawarkan dalam sebuah game menjadi salah satu alasan mengapa belajar melalui sebuah game akan banyak diminati oleh peserta didik. Akan tetapi membuat dan mengintegerasikan game dalam kurikulum pembelajaran tidaklah mudah dan membutuhkan waktu yang lama. Salah satu solusi yang peneliti usulkan adalah dengan menerapkan mekanik game khususnya board game ke dalam sistem pembelajaran dengan menggunakan metode gamifikasi. Gamifikasi dapat didefinisikan sebagai suatu proses yang menggunakan pemikiran dan mekanika permainan untuk mengikat user dan menyelesaikan masalah. Secara lebih detail Kapp mendefinisikan gamifikasi sebagai konsep yang menggunakan mekanika berbasis permainan, estetika dan permainan berfikir untuk mengikat orang-orang, tindakan memotivasi, mempromosikan pembelajaran dan menyelesaikan masalah (Kapp, 2012).

Prambayun membuat sebuah model gamifikasi untuk sistem manajemen pembelajaran dengan menggunakan MDA Framework yang digunakan untuk mengelola kegiatan pembelajaran. Mekanik permainan yang digunakan adalah Storytelling, Completing Quest, Leveling Up,
Achievment (Badge, Status, Final Point), Collecting Rewards, Earn \& Burn, Competition (Leaderboard \& Duel Quiz), Reminder dan Forum Activity (Prambayun et al., 2016).

M. Setiyawan membahas tentang penerapan gamifikasi dalam aplikasi perkuliahan dengan metode Feature Driven Development. Hal ini didasarkan pada meningkatnya ketertarikan mahasiswa terhadap game online pada saat ini, sehingga hal ini bisa diterapkan dalam sebuah aplikasi yang dapat membuat mahasiswa lebih berpartisipasi dalam perkuliahan dan membuat perkuliahan lebih menyenangkan. Pengujian aplikasinya menggunakan pengujian blackbox dan pengujian beta (Setiyawan et al., 2019). Pemrograman Animasi komputer dianggap sebagai kompetensi penting bagi pengembangan keterampilan pemecahan masalah selain penalaran logis (Pratama, 2018).

Naimah dkk, mengembangkan game edukasi berbasis boardgame berupa papan permainan dilengkapi dengan kartu seperti permainan monopoli, untuk meningkatkan ketrampilan pemecahan masalah siswa (Naimah \& Dkk, 2019). Sedangkan Najib mengembangkan media pembelajaran board game berbasis augmented reality dengan menggunakan model pengembangan ADDIE. Penelitian ini menghasilkan media embelajaran berupa board game berbasis augmented reality. Hasil unjuk kerja media pembelajaran board game berbasis augmented reality dengan blackbox testing (Najib \& Yunerti, 2018).

Berdasarkan uraian diatas, maka
perlu dikembangkan media
pembelajaran yang lebih inovatif dan
menuntut keaktifan peserta didik yang
akan meningkatkan motivasi belajar
peserta didik, maka peneliti
mengusulkan penelitian dengan judul


"Arsitektur Board Game Edukasi Sebagai Unsur Gamifikasi Pembelajaran untuk Membangun Partisipasi Aktif, Motivasi, dan Minat Belajar Siswa”.

\section{METODE PENELITIAN}

Penelitian ini menggunakan metode penelitian pengembangan. Model pengembangan yang digunakan adalah ADDIE (Analyze, Design, Develop, Implement, Evaluate) yang diadopsi dari William W. Lee dan Diana L. Owens.

1. Tahap analisis

Tahap analisis dilakukan terhadap beberapa komponen, yaitu : 1) menganalisis latar belakang peserta didik, 2) menganalisis media pembelajaran yang digunakan, 3) menganalisis teknologi informasi sekolah, 4) menganalisis pemilihan media, dan 5) menganalisis Kompetensi Inti dan Kompetensi Dasar.

2. Tahap Desain

Tahap desain dilakukan dengan merancang media pembelajaran interaktif yang meliputi pembuatan desain tampilan, pembuatan flowchart dan storyboard.

3. Tahap Pengembangan

Pengembangan dalam model ADDIE berisi kegiatan realisasi rancangan produk. Pada tahap pengembangan, kerangka yang bersifat konseptual direalisasikan menjadi produk yang siap diimplementasikan

4. Tahap Implementasi

Tahap implementasi adalah tahapan pembuatan media pembelajaran sesuai dengan yang telah direncanakan sebelumnya. Pada tahapan ini dilakukan validasi oleh ahli media dan ahli materi guna mendapatkan saran dan perbaikan untuk media pembelajaran.Setelah media pembelajaran diuji oleh ahli media dan ahli materi maka media pembelajaran masuk pada tahap revisi, yaitu perbaikan pada media pembelajaran berdasarkan masukan dari ahli materi dan ahli media.

5. Tahap Evaluasi

Tahap evaluasi bertujuan untuk menguji boardgame pembelajaran yang telah dikembangkan kepada pengguna apakah sudah sesuai dengan tujuan penelitian ini, yaitu meningkatkan Partisipasi Aktif, Motivasi, dan Minat belajar peserta didik setelah menggunakan boardgame pembelajaran ini.

Pada penelitian ini, pengambilan data dilakukan dengan wawancara kepada guru-guru, observasi langsung ke sekolah dan dokumentasi. Data-data tersebut digunakan untuk proses analisis awal meliputi, analisis proses belajar dan hasil belajar siswa.

Gambar 1 berikut merupakan gambar alur penelitian yang dilakukan. Alur tersebut menggambarkan tahapan yang dilakukan penelitia dari awal analisis hingga tahap implementasi dan evaluasi. 


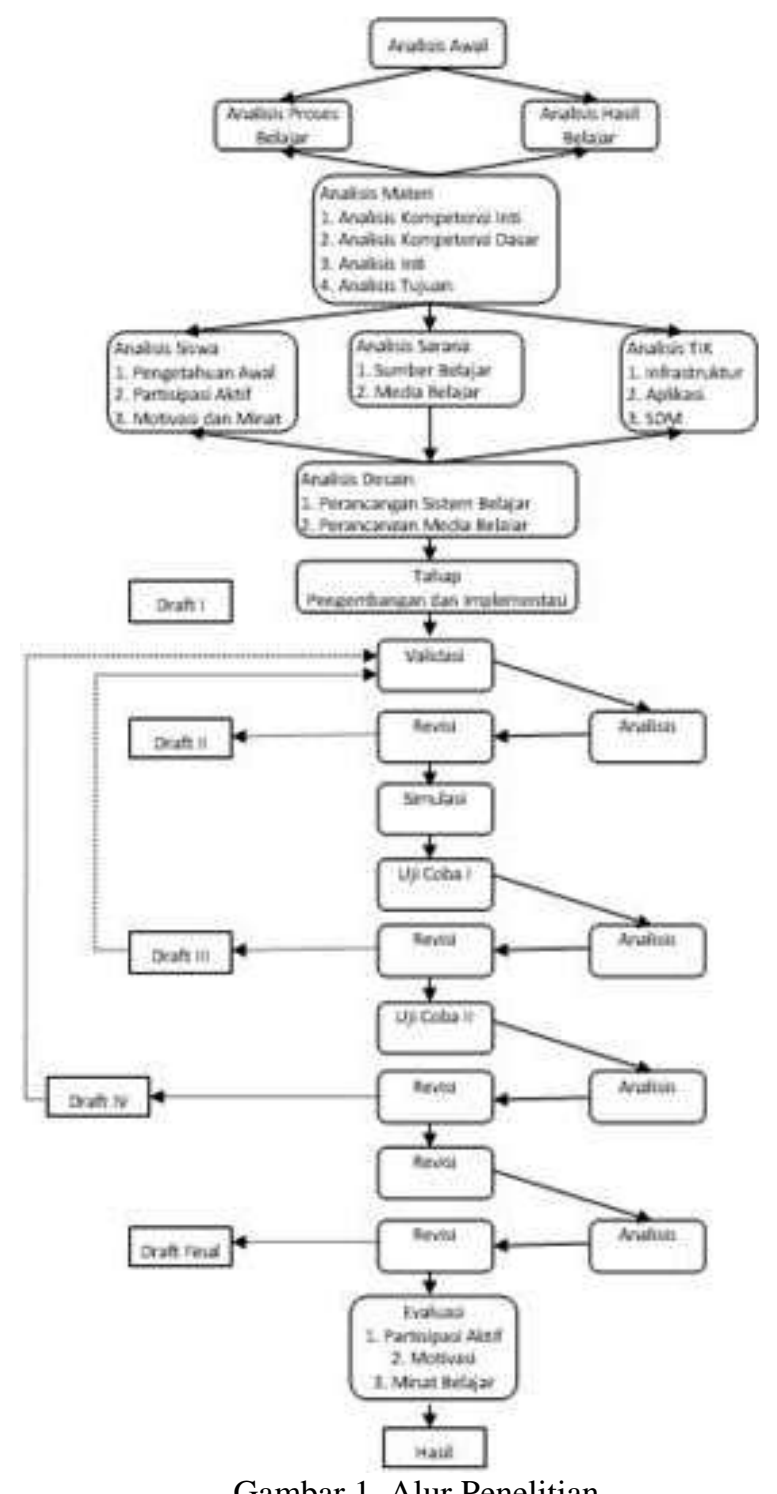

Gambar 1. Alur Penelitian.

\section{HASIL DAN PEMBAHASAN}

Tahap Analisa

Pada obyek penelitian di SD Negeri 2 Tlogorandu saat ini total jumlah peserta didik 56 siswa dengan pembagian 32 siswa laki-laki dan 24 siswi perempuan. Hal ini dikarenakan ada 5 Sekolah Dasar yang berada di kelurahan Tlogorandu dan lokasi sekolah yang agak jauh dengan pemukiman di sekitarnya, sehingga jumlah siswa tidak begitu banyak.
Tabel 1. Jumlah Siswa Berdasarkan Usia

\begin{tabular}{|l|c|c|c|}
\hline \multicolumn{1}{|c|}{ Usia } & L & P & Total \\
\hline$<6$ tahun & 3 & 0 & 3 \\
\hline $6-12$ tahun & 28 & 24 & 52 \\
\hline $\begin{array}{l}13-15 \\
\text { tahun }\end{array}$ & 1 & 0 & 1 \\
\hline Total & 32 & 24 & 56 \\
\hline
\end{tabular}

SD Negeri 2 Tlogorandu saat ini menggunakan Kurikulum 13 berdasarkan SK Kepala Sekolah nomor 421.2/46/VI/2020 tanggal 1 Juli 2020 tentang Penetapan dan Pemberlakuan Kurikulum Sekolah SD Negeri 2 Togorandu. Dimana struktur kurikulumnya dapat dilihat pada gambar berikut :

\begin{tabular}{|c|c|c|c|c|c|c|}
\hline \multirow[t]{2}{*}{ MATA FELANARAN } & \multicolumn{6}{|c|}{$\begin{array}{l}\text { ALOKASI WAKTE BEL.WAR } \\
\text { PER AIINGGU }\end{array}$} \\
\hline & 1 & II & III & IV & $\mathrm{v}$ & vi \\
\hline \multicolumn{7}{|l|}{ Kelompos: A } \\
\hline 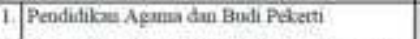 & 4 & 4 & 4 & 4 & 4 & 4 \\
\hline 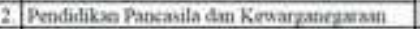 & 5 & 5 & 6 & 4 & 4 & 4 \\
\hline 3. Fatura labonetia & 8 & 9. & 10 & 7 & 7 & 7 \\
\hline 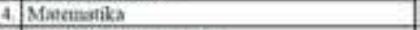 & 5 & 6 & 6. & 6 & 6 & 6 \\
\hline 5. Ilmo Pengetalusat Alam &. & $=$ & $=$ & 3 & 3 & 3 \\
\hline \begin{tabular}{l|l} 
6. Drum Penastabien Sosial \\
\end{tabular} & - & - & $=$ & 3 & 3 & 3 \\
\hline \multicolumn{7}{|l|}{ Kelompol B } \\
\hline 1. Seut Buidsya dun Priboinga & 4 & 4 & 4 & 5 & 5 & 5 \\
\hline 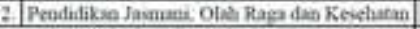 & 4 & 4 & 4 & 4 & 4 & 4 \\
\hline Jumbah Alokand Whise Per Mfinges & 30 & 32 & 34 & 36 & 36 & 36 \\
\hline
\end{tabular}

Gambar 2. Struktur Kurikulum 13

Dari daftar kurikulum 13 tersebut,dibagi lagi menjadi beberapa tema dan alokasi waktu sesuai dengan tingkat kelas masing-masing, mulai dari tingkat 1 sampai dengan tingkat 6 , seperti pada gambar berikut ini :

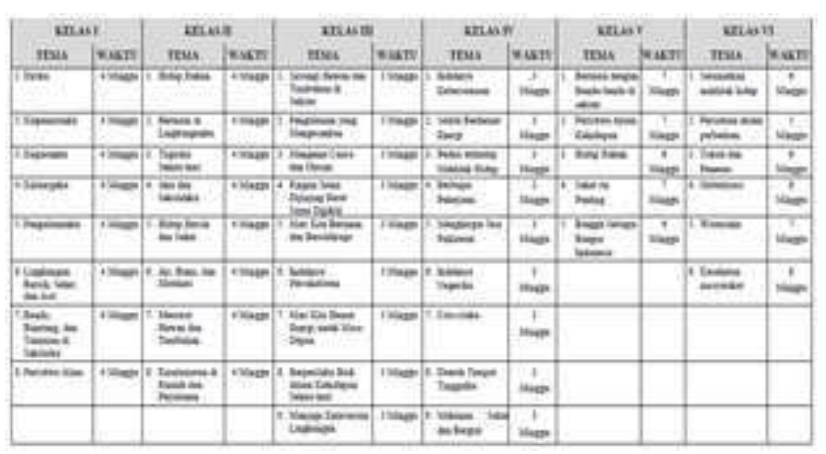

Gambar 3. Daftar tema dan alokasi waktu 
Dalam situasi pandemi Covid-19 ini, penerapan kurikulum 13 tersebut ditemukan beberapa kendala dikarenakan keterbatasan pertemuan antara guru dan siswa, sehingga penyampaian materi pembelajaran kurang maksimal, hal ini dapat dilihat dari hasil angket yang diberikan kepada guru kelas mengenai pemahaman siswanya terhadap pembelajaran sebagai berikut :

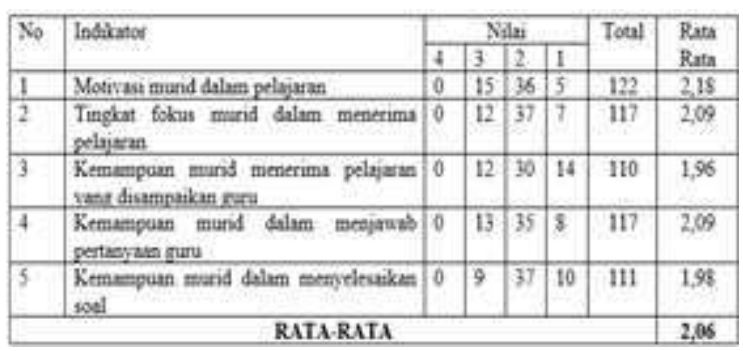

Gambar 4. Hasil Evaluasi Tingkat Partisipasi Siswa

Dari angket tersebut, dapat dilihat bahwa tingkat partisipasi siswa dalam pembelajaran masih relatif rendah, yaitu masih dibawah 3. Maka dari itu dibutuhkan suatu tehnik baru untuk dapat meningkatkan tingkat partisipasi siswa dalam pembelajaran, agar minat siswa terhada pelajaran juga dapat meningkat.

\section{Tahap Desain}

Berdasarkan hasil angkat pada Tabel 4 diatas penulis membuatkan arsitektur boardgame yang disesuaikan dengan kurikulum yang digunakan yaitu Kurikulum 13 dengan materi seperti yang tertera gambar 2 di atas. Adapun sketsa rancangan yang dibuat adalah sebagai berikut :

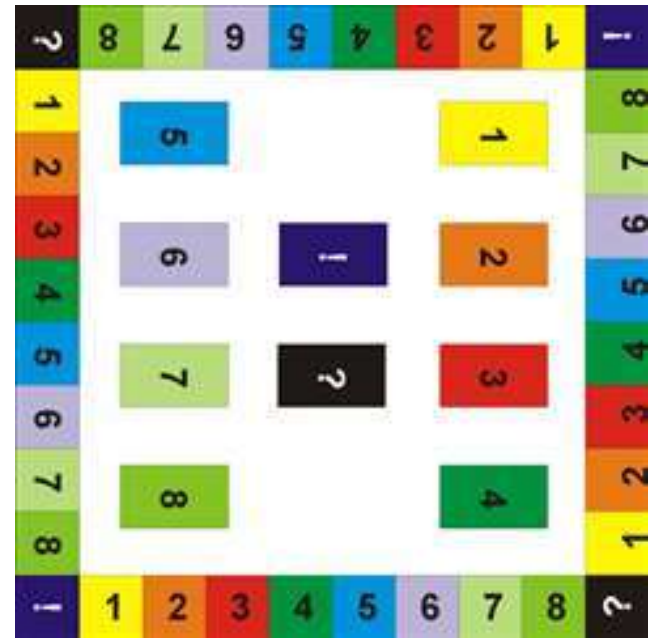

Gambar 5. Draft Desain Boardgame Pembelajaran
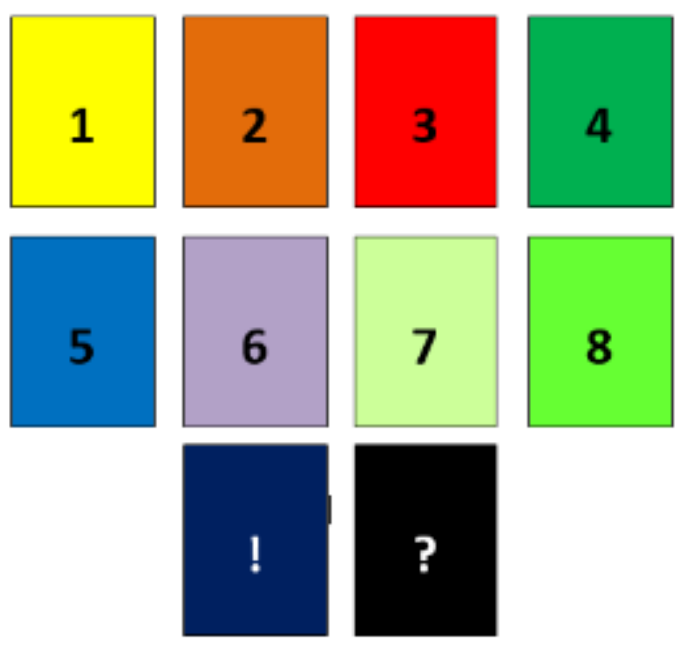

Gambar 6. Desain Kartu ertanyaan

\section{Gameplay dan game mechanic yang digunakan}

\section{Gameplay}

Permainan terdiri dari papan permainan, kartu pertanyaan, dadu, bidak, koin, badge, serta papan penunjuk nilai atau skor.kartu pertanyaan terdiri dari 10 jenis kartu, 8 kartu sesuai dengan jumlah pelajaran dalam kurikulum 13, 2 kartu sebagai kartu bonus. Pada masing-masing tumpukan kartu terdapat 10 buah kartu dengan nomor 1 sampai dengan 10. Kartu tersebut diambil dari tumpukan kartu sesuai dengan angka terakhir bidak berhenti setelah berjalan sesuai dengan angka 
dadu. Jadi sebelum permainan dimulai, guru terlebih dahulu menyiapkan pertanyaan dengan skema seperti pada tabel berikut :

Tabel 2. Daftar Pertanyaan Permainan

\begin{tabular}{|c|c|c|c|}
\hline No & Pelajaran & Pertanyaan & Jawaban \\
\hline \multirow[t]{10}{*}{1} & \multirow{10}{*}{$\begin{array}{l}\text { Pendidikan Agama } \\
\text { dan Budi Pekerti }\end{array}$} & 1 & \\
\hline & & 2 & \\
\hline & & 3 & \\
\hline & & 4 & \\
\hline & & 5 & \\
\hline & & 6 & \\
\hline & & 7 & \\
\hline & & 8 & \\
\hline & & 9 & \\
\hline & & 10 & \\
\hline \multirow[t]{10}{*}{2} & \multirow{10}{*}{$\begin{array}{l}\text { Pendidikan } \\
\text { Pancasila dan } \\
\text { Kewarganegaraan }\end{array}$} & 1 & \\
\hline & & 2 & \\
\hline & & 3 & \\
\hline & & 4 & \\
\hline & & 5 & \\
\hline & & 6 & \\
\hline & & 7 & \\
\hline & & 8 & \\
\hline & & 9 & \\
\hline & & 10 & \\
\hline . & $\begin{array}{l}\text { Dan seterusnya } \\
\text { sampai } 8 \text { mata } \\
\text { pelajaran }\end{array}$ & & \\
\hline \multirow[t]{10}{*}{8} & \multirow{10}{*}{$\begin{array}{l}\text { Pendidikan } \\
\text { Jasmani, Olahraga } \\
\text { dan kesehatan }\end{array}$} & 1 & \\
\hline & & 2 & \\
\hline & & 3 & \\
\hline & & 4 & \\
\hline & & 5 & \\
\hline & & 6 & \\
\hline & & 7 & \\
\hline & & 8 & \\
\hline & & 9 & \\
\hline & & 10 & \\
\hline \multirow[t]{10}{*}{$?$} & \multirow{10}{*}{$\begin{array}{l}\text { Pertanyaan Bonus } \\
\text { Materi bebas }\end{array}$} & 1 & \\
\hline & & 2 & \\
\hline & & 3 & \\
\hline & & 4 & \\
\hline & & 5 & \\
\hline & & 6 & \\
\hline & & 7 & \\
\hline & & 8 & \\
\hline & & 9 & \\
\hline & & 10 & \\
\hline \multirow[t]{10}{*}{$!$} & \multirow{10}{*}{$\begin{array}{l}\text { Tugas Bonus } \\
\text { Materi bebas }\end{array}$} & 1 & \\
\hline & & 2 & \\
\hline & & 3 & \\
\hline & & 4 & \\
\hline & & 5 & \\
\hline & & 6 & \\
\hline & & 7 & \\
\hline & & 8 & \\
\hline & & 9 & \\
\hline & & 10 & \\
\hline
\end{tabular}

Sebelum pemainan dimulai, siswa dibagi menjadi 4 kelompok sesuai dengan jumlah bidak yang ada dalam permainan. Setiap kelompok diberikan modal 10 koin untuk memulai permainan. Permainan dimulai dengan suit antar kelompok untuk menentukan urutan permainan. Setelah ditemukan urutan permainan, kelompok pertama melemparkan dadu dan bidak dijalankan sesuai dengan nomor dadu yang didapatkan.

Siswa diharuskan menjawab pertanyaan tersebut. Jika pertanyaan dijawab dengan benar maka kartu pertanyaan disimpan oleh siswa dan diberikan poin berupa bintang. Jika tidak bisa menjawab maka siswa mengembalikan kartu pertanyaan ke tumpukan semula posisi paling bawah. Yang menjadi pemenang daam permainan ini adalah siswa yang mendapatkan poin paling banyak dan mendapatkan kartu pertanyaan paling banyak.

\section{Game Mechanic}

Selanjutnya Game mechanics yang diterapkan dalam aplikasi perkuliahan ini sebagai berikut:

a. Dadu

Untuk memulai langkah pemaian digunakan satu buah dadu yang dilemparkan sehingga menunjuk angka tertentu untuk pemain melangkahkan bidaknya.

b. Bidak

Bidak menunjukkan simbol satu kelompok, agar beda dengan kelompok yang lain.

c. Koin

Koin akan didapatkan siswa dengan menjawab pertanyaan dalam permainan, jika mendapkan kartu $1-8$ maka akan mendapatkan koin 1 buah, jika mendapatkan kartu Pertanyaan Bonus,maka akan 
mendapatkan 2 koin, dan untuk kartu Tugas Bonus akan mendapatkan 3 koin.

d. Bintang

Setiap 10 koin yang didapatkan siswa dapat ditukarkanmenjadi bintang.

e. Challenge

Pada setiap nomor yang ditempati bidak terdapat kartu yang berisi pertanyaanpertanyaan yang harus dijawab oleh pemain sesuai dengan materi yang ada pada kartu permainan.

f. Obstacle

Halangan-halangan yang ada pada permainan diantaranya, harus menjawab pertanyaan atau tugas yang ada dalam setiap kartu permainan, dan harus menjawab dengan benar, karena jika salah, koin yang didapat akan dikurangi 1.

g. Leaderboard

Setiap koin dan kartu permainan yang berhasil dijawab akan dilatekkan pada papan peringkat, sehingga bisa digunakan untuk memotivasi pemain yang lain untuk bisa saling bersaing.

h. Badges

Pada akhir permainan, berdasarkan leaderboard yang ada, maka akan diberikan badges sesuai dengan peringkat akhir. Terdiri dari 4 badges yaitu Raja, Ratu, Menteri dan Ksatria

Tabel 3. Jenis Bagdes yang Digunakan

\begin{tabular}{|c|c|c|c|}
\hline No & $\begin{array}{c}\text { Bagd } \\
\text { es }\end{array}$ & $\begin{array}{c}\text { Peringka } \\
\text { t }\end{array}$ & Simbol \\
\hline 1 & $\begin{array}{l}\text { Ksatri } \\
\text { a }\end{array}$ & 4 & \\
& & & \\
\end{tabular}

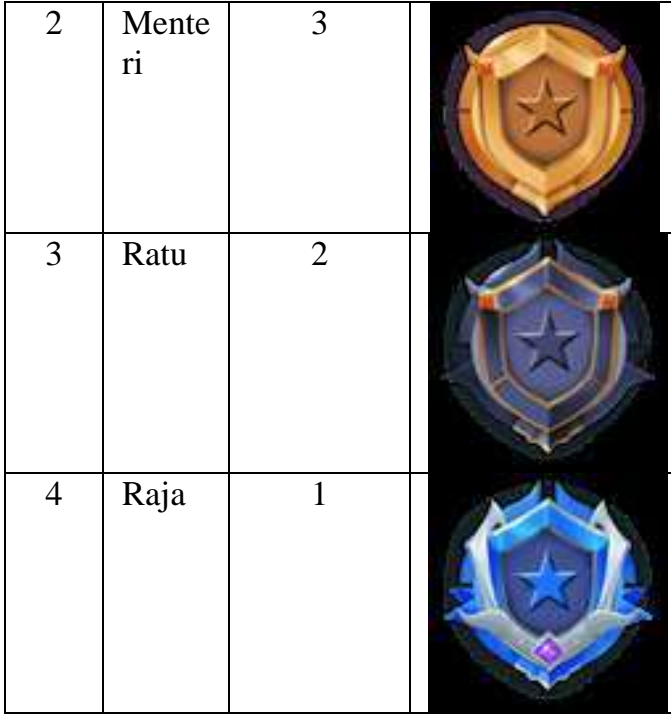

\section{Flowchart Gamplay}

Dari gameplay yang sudah dijelaskan dapat digambarkan flowchart alur permainan dalam boardgame pembelajaran sebagai berikut :

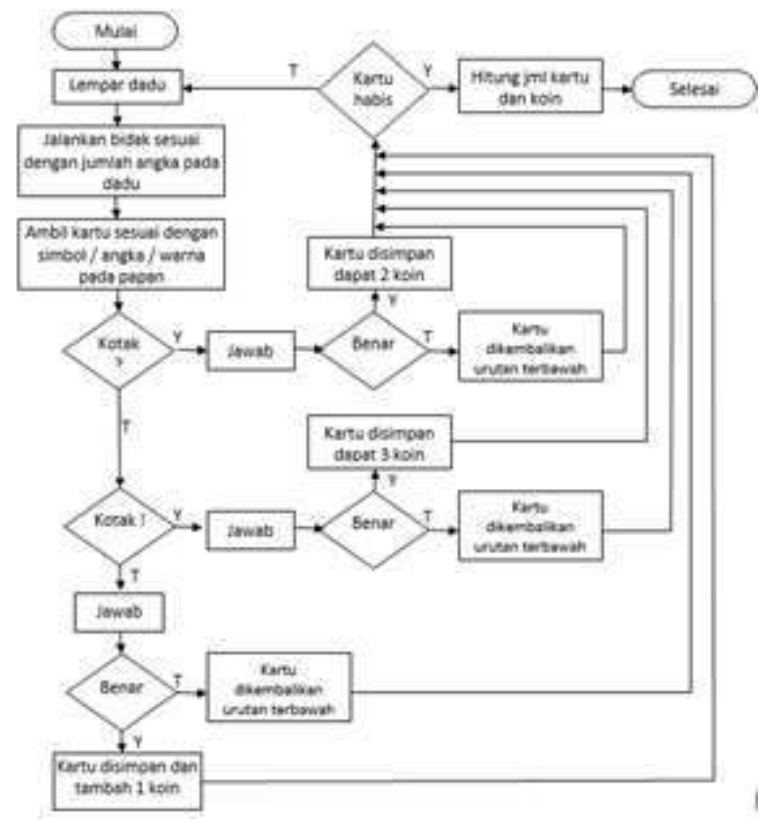

Gambar 7. Flowchart Gameplay

\section{Tahap Pengembangan}

Setelah tahap desain permainan selesai, tahap berikutnya adalah pengembangan. Tahap ini berisi tentang tindak lanjut dari desain permainan yang sudah ditentukan sebelumnya, yaitu 
dengan membuat desain lebih menarik agar siswa nantinya lebih tertarik untuk berpartisipasi dalam permainan ini.

a. Dadu

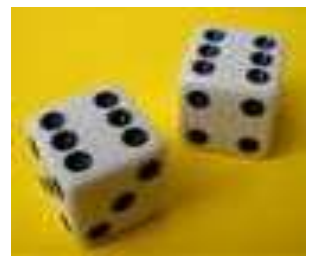

Gambar 8. Dadu Permainan

b. Bidak

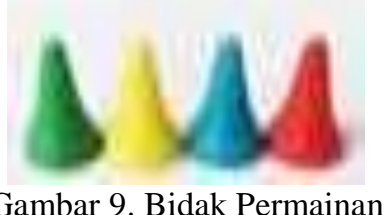

Gambar 9. Bidak Permainan

\section{c. Papan Permainan}

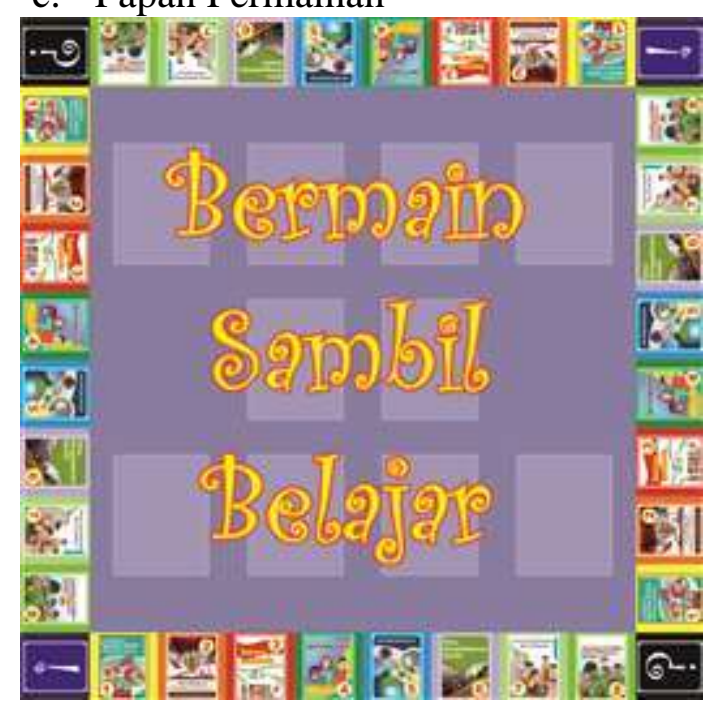

Gambar 10. Desain Akhir Papan Permainan

d. Kartu

Kartu terdiri dari 8 kartu mata pelajaran dan 2 kartu bonus. Masingmasing kartu terdiri dari 10 kartu yang berisi nomor pertanyaan $1-10$ didalam satu tumpukan kartu.

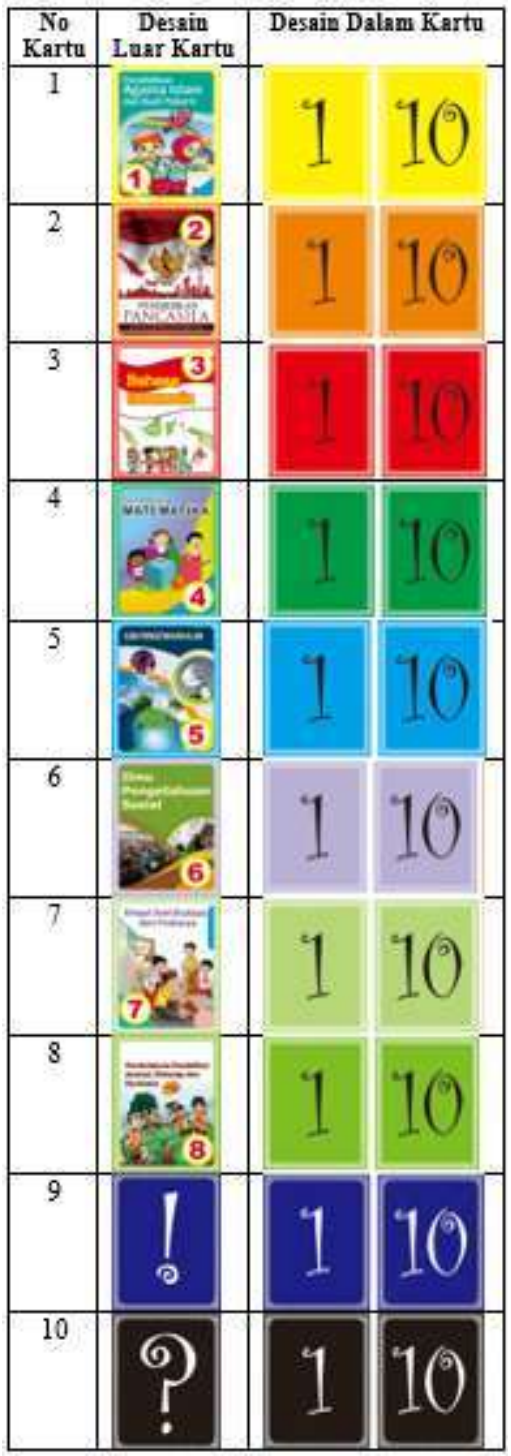

Gambar 11. Desain Akhir Kartu Permainan

e. Papan Peringkat

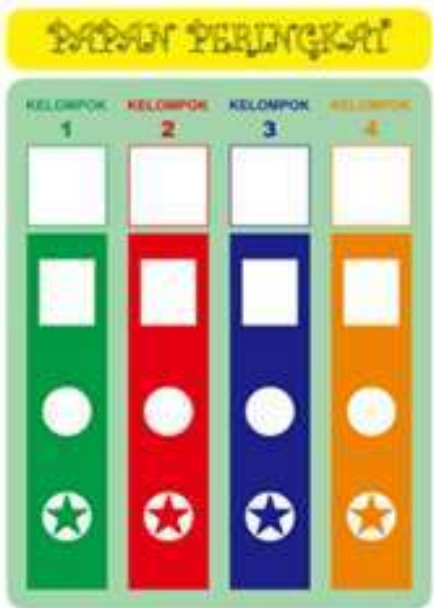

Gambar 12. Desain akhir papan peringkat 
f. Kartu Badges

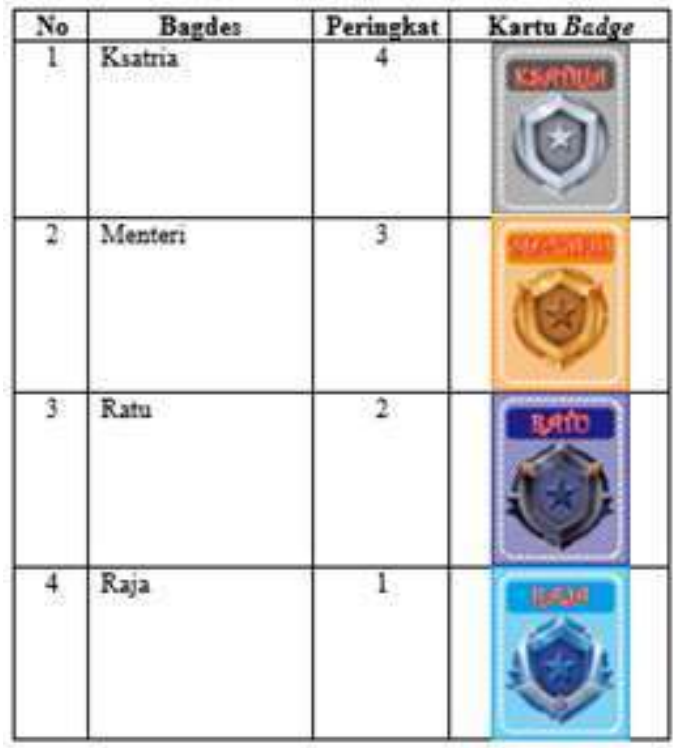

Gambar 13. Desain Akhir Badge

\section{Tahap Implementasi}

Setelah desain akhir sudah jadi, maka tahap berikutnya adalah menerapkan boardgame permainan ke dalam pembelajaran. Sebelum diimplementasikan dalam pembelajaran, terlebih dahulu diadakan pertemuan dengan guru kelas untuk mensosialisasikan tentang alur permainan dalam boardgame pembelajaran ini dari awal sampai dengan akhir sampai guru paham dengan alur permainannya, karena untuk selanjutnya pelaksanaan permainan ini akan langsung diampu oleh guru kelas masing-masing. Hasil pengujian yang dilakukan oleh guru kelas tercantum dalam tabel berikut ini :

Tabel 4. Hasil Pengujian Boardgame

\begin{tabular}{|c|c|c|}
\hline $\mathrm{So}_{0}$ & Gameplay & $\mathrm{Haxil}_{\mathrm{j}}$ \\
\hline 1. & Mentawali permainat & $\begin{array}{l}\text { Dapat dilakikan ieved: } \\
\text { fturan }\end{array}$ \\
\hline 2. & $\begin{array}{l}\text { Mentambil kartu sevuai deagan betentinya } \\
\text { lanplab bidak permainan }\end{array}$ & $\begin{array}{l}\text { Dapat dilakukan ietuai } \\
\text { aturan }\end{array}$ \\
\hline 3. & Havil yang diberikan jika jawaban betar & $\begin{array}{l}\text { Dapat dilakokan sesusi } \\
\text { aturan }\end{array}$ \\
\hline 4 & Hasil yang diberikan jika jawaban salah & $\begin{array}{l}\text { Dapat dilahikan sesuail } \\
\text { aturan }\end{array}$ \\
\hline 5. & $\begin{array}{l}\text { Hanl yang dibenikan untukik pertangyas dan } \\
\text { tugas bonas }\end{array}$ & $\begin{array}{l}\text { Dapat dilakekan atioxi } \\
\text { aturan }\end{array}$ \\
\hline 6 , & Pentaras koin dentas bintang & $\begin{array}{l}\text { Dapat dilakikan ivesi } \\
\text { aturan }\end{array}$ \\
\hline 3 , & $\begin{array}{l}\text { Pemberian badges untuk petzain di akhin } \\
\text { permainas }\end{array}$ & $\begin{array}{l}\text { Dapat dilakekan novai } \\
\text { aturan }\end{array}$ \\
\hline 8. & Meneatukan petwenan permainan & $\begin{array}{l}\text { Dapat dilakukan sevua: } \\
\text { aturan }\end{array}$ \\
\hline
\end{tabular}

Setelah guru dapat mengampu sendiri permainan ini, untuk tahap awal boardgame pembelajaran diimplementasikan untuk siswa kelas 3, 4, 5 dan siswa kelas 6 SD $\mathrm{N} 2$ Tlogorandu. Permainan diampu oleh guru kelas masing-masing, dilaksanakan setiap minggu sekali pada hari Sabtu. Materi yang diajarkan selama sepekan akan dirangkum dalam bentuk pertanyaan dan jawaban yang dikemas dalam tabel seperti pada Tabel 2 di atas.

\section{Evaluasi}

Dari sampling yang dilakukan selama 1 bulan terhadap 4 kelas tersebut, kemudian dilakukan pengisian angket oleh guru kelas dengan memperhatikan partisipasi siswa di kelas masingmasing, hasilnya tercantum dalam tabel berikut :

Jumlah siswa kelas 3, 4, 5, dan 6 adalah 34 siswa

\begin{tabular}{|c|c|c|c|c|c|c|c|}
\hline \multirow[t]{2}{*}{ No } & \multirow{2}{*}{ Indikator } & \multicolumn{4}{|c|}{ Nilai } & \multirow[t]{2}{*}{ Total } & \multirow{2}{*}{$\begin{array}{l}\text { Rata } \\
\text { Rata }\end{array}$} \\
\hline & & 4 & 3 & 2 & 1 & & \\
\hline 1 & Motrivasi murid dalam pelojaran & 10 & 16 & 6. & 2 & 102 & 3.00 \\
\hline 2 & $\begin{array}{l}\text { Tingkat fohas murid dalam menerima } \\
\text { pelajuran }\end{array}$ & 12 & 15 & 4. & 3 & 104 & 3.06 \\
\hline 3 & $\begin{array}{l}\text { Kensanpoun murid menerima pelajaran } \\
\text { vang disumpakanguru }\end{array}$ & 13 & 11 & 5 & 5 & 100. & 2.94 \\
\hline 4 & $\begin{array}{l}\text { Kemampasn murid dalam menjswab } \\
\text { pertasyas guru }\end{array}$ & 17 & 5 & 9 & 3 & 104 & 3.06 \\
\hline 5 & $\begin{array}{l}\text { Kemampaan murid dalam menyelesaikan } \\
\text { soal } \\
\text { RATA-RATA }\end{array}$ & 15 & 7 & 8 & 4 & 101. & $\frac{2,97}{3.01}$ \\
\hline
\end{tabular}

Gambar 14. Hasil Evaluasi Tingkat Partisipasi Siswa Setelah Penggunaan Boardgame

\section{PENUTUP}

\section{Kesimpulan Dan Saran}

Dari hasil penilaian dari guru kelas ada Tabel 10 tersebut, dapat diambil kesimpulan bahwa setelah menggunakan boardgame pembelajaran selama 1 bulan tingkat partisipasi siswa meningkat dari yang awalnya hanya 2,06 sekarang menjadi 3,01. Sehingga dapat dikatakan penggunaan boardgame pembelajaran ini dapat meningkatkan tingkat partisipasi aktif, motivasi dan minat belajar siswa dalam pembelajaran. 
Saran untuk selanjutnya, diharapkan guru kelas dapat lebih kreatif untuk menyusun pertanyaan-pertanyaan yang akan digunakan dalam boardgame pembelajaran tersebut, sehingga siswa jadi lebih termotivasi untuk mengikuti pembelajaran.

\section{Ucapan Terima Kasih}

Penelitian ini dibiayai oleh :

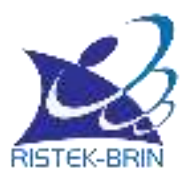

\section{DAFTAR PUSTAKA}

Arsyad, A. (2015). Media Pembelajaran. PT. Raja Grafindo Persada.

Kapp, K. . (2012). The Gamification of Learning and Instruction: Gamebased Methods and Strategies for Training and Education. John Wiley \& Sons.

Naimah, J., \& Dkk. (2019). Pengembangan Game Edukasi Science Adventure untuk Meningkatkan Kemampuan Pemecahan Masalah Siswa. Jurnal Pendidikan Sains Indonesia (Indonesian Journal of Sciences Education), 7(2).

Najib, A., \& Yunerti, N. (2018). Pengembangan Media Pembelajaran Board Game Berbasis Augmanted Reality Pada Mata Pelajaran Teknik Dasar Listrik dan Elektronika di Sekolah Menengah Kejuruan. Jurnal Program Studi Pendidikan Teknik
RISTEK-BRIN sesuai dengan Surat Keputusan Nomor 150615/A.A2/KU/2019 dan Kontrak Nomor 074/LL6/PG/SP2H/PL.II/2020.

Terima kasih juga kepada LPPM STMIK Amikom Surakarta yang telah membantu dan mendampingi dalam proses penelitian ini. Serta terima kasih kepada JOINED (Journal of Informatic Education) yang telah mempublikasikan hasil penelitian ini.

Mekatronika, 8 .

Pratama, A. (2018). Pengaruh Pengajaran Pemrogaman Animasi melalui Aplikasi Scratch pada Kemampuan Pemecahan Masalah. Joined Journal (Journal Of Informatics Education), 1(1), 2431. doi:10.31331/joined.v1i1.613

Prambayun, A., Suyanto, M., \& Sunyoto, A. (2016). Model Gamifikasi Untuk Sistem Manajemen Pembelajaran. Seminar Nasional Teknologi Informasi Dan Multimedia, STMIK AMIKOM Yogyakarta.

Setiyawan, M., Winarno, W. W., \& Sunyoto, A. (2019). Implementasi Gamification pada Aplikasi Perkuliahan Mahasiswa dengan Metode Feature Driven Development (Studi Kasus : AMIK Cipta Darma Surakarta). IT Cida, 5.

Sukiman. (2012). Pengembangan Media Pembelajaran. Pedagogia. 